\title{
PENGELUARAN PUBLIK INDONESIA: TINJAUAN MAQASID SYARIAH
}

\author{
Annisa Masruri Zaimsyah ${ }^{1}$ \\ Syahbuddin ${ }^{2}$ \\ 12 Sekolah Tinggi Agama Islam Hubbulwathan Duri \\ Email: annisamasruri@gmail.com ${ }^{1}$; syahbuddin83@gmail.com²
}

\begin{abstract}
Introduction: Public expenditure management in Indonesia has implemented a distribution system that divides public expenditures for central government spending, transfers to regions, and village funds. This study discusses public spending in Indonesia in the Indonesian National Budget. The data is collected from fiscal policy documentation, especially about government spending plans in 2018, and then policy analysis, public spending theory and get conclusions.

Methods: This study uses a qualitative research method with a descriptive approach. The type of data used is secondary data. The techniques used in data collection in this research include literature study, documentary, discussion, and intuitive-subjective.

Results: Fiscal policy priorities for public spending to support the achievement of sustainable economic growth, job creation, poverty reduction, and reducing inequality in the welfare of the whole society. In the view of Maqasid sharia, public expenditure is used to meet the five human needs, namely religion, soul, mind, lineage and property. Public spending on the Indonesian government as an effective tool to generate economic resources and increase the income of society as a whole by focusing on realizing the objectives of Maqasid Syariah

Conclusion and suggestion: The purpose of public spending in Indonesia in general is in accordance with maqasid sharia, but not yet fully in accordance with the goals of Islam, such as in terms of religion, in Islam religion is the peak for public spending, while in Indonesia public expenditure religion gets a very large portion. a little, besides that in Islam there is also a surplus system, and Indonesia is a deficit, this makes the objectives of budget expenditure a little different.
\end{abstract}

Keywords: Maqasid Syariah, Fiscal Policy, Public Expenditure 


\section{PENDAHULUAN}

Pada dasarnya, anggaran menempati posisi yang signifikan dan strategis dalam administrasi untuk keberlangsungan urusan suatu negara. APBN adalah dokumen kebijakan yang dinyatakan dalam istilah keuangan yang berisi estimasi pendapatan dan pengeluaran pemerintah untuk periode tertentu, biasanya satu tahun. ${ }^{1}$

Anggaran pendapatan dan Belanja Negara (APBN) pada hakekatnya merupakan pelaksanaan kebijakan keuangan Negara yang secara konstitusional diatur dalam pasal 23 Undang-undang Dasar Tahun 1945 dan dituangkan di dalam Garis-garis besar Haluan Negara (GBHN), serta diterjemahkan secara kuantitatif dalam Repelita. Dalam kajian tersebut, APBN yang undang-undangnya ditetapkan setiap tahun secara politis merupakan bentuk amanat rakyat, dan secara ekonomis harus mampu diterjemahkan pengelolaannya secara tepat dalam perekonomian Nasional.

Pengeluran publik secara rill dapat digunakan sebagai indikator ukuran kegiatan pemerintah yang dibiayai oleh pemerintah. Semakin besar dan semakin banyak kegiatan maka semakin besar pula pengeluran publik tersebut. Tetapi harus disadari bahwa proporsi pengeluaran publik terhadap pendapatan Nasional bruto adalah ukuran yang sangat kasar dari kegiatan atau peran pemerintah dalam bentuk ekonomi. ${ }^{2}$

Sejak masa Nabi dan masa-masa khalifah dan berikutnya, pengelolaan keuangan Negara dalam wujudnya sekarang ini berupa APBN, telah memiliki mekanisme dan pengelolaan anggaran yang bersifat khas yang sesuai dengan situasi dan konsisi sosial, politik, dan budaya. Namun, aspek-aspek pengelolaan anggaran yang bersifat umum, tentunya sangat sesuai dalam upaya memaksimalkan peran Negara melalui anggaran untuk mensejahterakan masyarakat.

Di Indonesia memang tidak menganut system anggaran dengan syariat Islam, akan tetapi muslim di Indonesia cukup banyak. Pengeluaran anggaran di Indonesia berdasarkan data dari Kemenkue tahun 2018 belanja Negara sebesar 2.220,7 T. pengeluaran terbesar adalah: 1). Belanja pemerintah pusat sebesar 1.454,5 T, 2). Transfer ke Daerah dan Dana Desa sebesar 776,2 T, 3). Pembiayaan Anggaran sebesar 325,9 T

Sehingga defisit anggaran sebesar 325,9 T seperti yang dijelaskan dalam tabel 1 Posture APBN 2018 dibawah ini:

Tabel 1 Postur APBN 2018

\begin{tabular}{|c|c|c|c|c|}
\hline \multirow{2}{*}{$\begin{array}{c}\text { Uraian } \\
\text { (triliun Rupiah) }\end{array}$} & 2017 & 2018 & \multirow{2}{*}{$\begin{array}{l}\text { \% thd } \\
\text { Outlook } \\
2017 \\
\end{array}$} & \multirow[t]{2}{*}{ Selisih } \\
\hline & Outlook & APBN & & \\
\hline Belanja Negara & $2.098,9$ & $2.220,7$ & 105,8 & 121,7 \\
\hline 1. Balanja Pemerintah Pusat & $1.343,1$ & $1.454,5$ & 108,3 & 111,4 \\
\hline
\end{tabular}

1 Ajibolade, S. O., \& Oboh, C. S. (2017). A critical examination of government budgeting and public funds management in Nigeria . International Journal of Public Leadership, 218-242.

2 Jaelani, A. (2017). Fiscal Policy in Indonesia: Analysis of State Budget 2017 in Islamic Economic Perspective. International Journal of Economics and Financial Issues , 14-24. 


\begin{tabular}{llllll}
\hline a. & Belanja K/L & 769,2 & 874,4 & 110,2 & 78,2 \\
b. Belanja Non K/L & 573,9 & 607,1 & 105,8 & 33,2 \\
1) & Pembiayaan Bunga Utang & 218,6 & 238,6 & 109,2 & 20,0 \\
2) & Subsidi & 168,9 & 156,2 & 92,5 & $(12,6)$ \\
3) Belnaja Lain-lain & 56,0 & 67,2 & 120,1 & 11,2 \\
\hline 2. & Tranver ke Daerah dan Dana Desa & 755,9 & 766,2 & 101,4 & 10,3 \\
$\quad$ a. Tranver Ke Daerah & & & & \\
$\quad$ a.i. a. Dana Bagi Hasil & Dana Alokasi Umum & 697,7 & 706,2 & 101,2 & 8,5 \\
b. Dana Desa & 95,4 & 89,2 & 93,5 & $(6,2)$ \\
$\quad$ & 398,6 & 401,5 & 100,7 & 2,9 \\
\hline Keseimbangan Primer & 58,2 & 60,0 & 103,1 & 1,8 \\
\hline
\end{tabular}

Sumber (Kemenkeu, 2018)

Indonesia mengalami anggaran defisit sebesar 2,19 ditahun 2018. Dalam Islam sesungguhanya anggaran surplus lebih baik dari pada anggaran defisit, akan tetapi kementrian keuangan Indonesia anggaran defisit Indonesia masih aman selama belum mencapai angka 5\%.

Anggaran Negara Pemerintah Republik Indonesia kurang sehat karena defisit utama dalam APBN 2017 yang mencapai Rp 111,4 triliun. Sri Mulyani menekankan bahwa keseimbangan utama defisit anggaran negara sebenarnya tidak baik, sehingga pemerintah harus berhati-hati. Neraca primer negatif menunjukkan bahwa pemerintah menunjukkan sejauh ini telah meminjam dana hanya untuk pembayaran utang. Jadi, pemerintah meminjam bukan untuk berinvestasi, tetapi untuk membayar hutang masa lalu. ${ }^{3}$

Penelitian terdahulu terkait anggaran sangat banyak dilakukan, dalam penelitian yang ditulis oleh Mitsuaki Furukawa dan Junichoir Takahata (2018) yang berjudul Dukungan Anggaran Publik di Tanzania: Implikasi dari Pencairan Terlambat untuk Layanan Pengiriman, hasilnya transfer dana dari pusat secara signifikan berkorelasi pada khususnya, hal ini menunjukkan bahwa pengeluaran pembangunan lebih berpengaruh berulang oleh keterlambatan transfer dana ke daerah. ${ }^{4}$

Solabomi Omobola dan Collins Sankay Oboh penelitian yang berjudul Sebuah pemeriksaan kritis terhadap penganggaran pemerintah dan pengelolaan dana publik di Nigeria, hasilnya bahwa pendekatan anggaran tahunan Negara cacat dan tertinggal dalam mencapai tujuan fiskal. Anggaran menunjukkan keadaan akuntabilitas dan transparansi yang tidak baik. ${ }^{5}$

\footnotetext{
${ }^{3}$ Jaelani, A. (2017). Fiscal Policy in Indonesia: Analysis of State Budget 2017 in Islamic Economic Perspective. International Journal of Economics and Financial Issues , 14-24.

${ }^{4}$ Furukawa, M., \& Takahata, J. (2018). General Budget Support in Tanzania Implications of late disbursements for service delivery. African Journal of Economic and Management Studies , 477-491.

5 Ajibolade, S. O., \& Oboh, C. S. (2017). A critical examination of government budgeting and public funds management in Nigeria. International Journal of Public Leadership, 218-242.
} 
Aan Jaelani penelitian yang berjudul Manajemen pengeluaran publik di Indonesia: Tinjauan ekonomi Islam tentang anggaran negara 2017, hasilnya menunjukkan bahwa Dalam ekonomi Islam, pengeluaran publik digunakan untuk memenuhi kebutuhan publik berdasarkan prinsip kepentingan publik. Pengeluaran publik ini sebagai alat yang efektif untuk mengalihkan sumber daya ekonomi dan meningkatkan pendapatan masyarakat secara keseluruhan. Pengeluaran publik ini terkait dengan peran pemerintah dalam menjalankan fungsinya, seperti mengatur kehidupan agama yang harmonis, penegakan hukum, perlindungan masyarakat, pemenuhan kebutuhan dasar, administrasi keuangan, dan pembangunan. Fungsi ini difokuskan pada perwujudan kehidupan masyarakat yang sejahtera.

Studi ini menganalisis manajemen pengeluaran publik, tujuan pengeluaran publik, dan sistem belanja pemerintah Indonesia dalam Anggaran Negara 2018, dan mengkaji secara komperatif dengan konsep belanja publik dalam pandangan Maqasid Syariah, sehingga dapat diketahui aspek fungsi dan praktik pengeluaran publik yang bertujuan untuk kemaslahatan masyarakat

\section{METODE PENELITIAN}

Studi ini menggunakan pendekatan kualitatif, yaitu penelitian yang tidak menggunakan penghitungan matematika, statistik dan lain sebagainya, akan tetapi menggunakan pendekatan ilmuah atau menganalisis penemuan-penemuan yang tidak dicapai menggunakan alat statistic. Pendekatan yang digunakan adalah pendekatan normatif, yaitu penelitian ekonomi normatif. Dimana terdapat data-data empiris, maka dimasukkan untuk mempertajam analisa dan menguatkan argumentasi penelitian.

\section{HASIL DAN PEMBAHASAN}

\section{Tujuan Pengeluran Publik Tahun 2018}

Tujuan pengeluaran publik secara umum terdapat 3 tujuan yaitu: 6 Pertama Mengalihkan belanja yang komsumtif menjadi belanja produktif dalam rangka akselaerasi pertumbuhan ekonomi saerta pencapaian realisasi belanja Negara, Kedua Efisiensi belanja dan peningkatan belanja produktif untuk mendukung program prioritas, Ketiga Melanjutkan penguat kualitas belanja Negara dan tetap konsisten melakukan efisiensi belanja non-prioritas tanpa mengurangi pencapaian sasaran output yang telah direncanakan.

Dilihat dari sisi anggaran yang dikeluarkan tahun 2018 pengeluaran publik atau belanja Negara terpusat pada belanja pemerintah pusat yang paling banyak. Pengeluaran publik pada tahun 2018 diarahkan kepada pembangunan nasional antara lain

6 Kemenkeu. (2018). Informasi APBN. Retrieved from Kementrian Keuangan Republik Indonesia: www.anggarankemenkue.go.id 
infrastruktur, penganguran, penhurangan kemiskinana, dalam rangka pemerataan pembangunan dan perbaikan konektivitas dengan tetap menjaga efisiensi.

Dalam Undang-Undang Republik Indonesia Nomor 18 Tahun 2016 tentang APBN 2017, disebutkan bahwa APBN adalah kewajiban pemerintah pusat yang diakui sebagai pengurangan terhadap kekayaan bersih terdiri dari pengeluaran pemerintah pusat dan transfer dana ke wilayah dan desa. Pengeluaran pemerintah pusat menurut fungsi adalah pengeluaran pemerintah pusat yang digunakan untuk melakukan fungsi pelayanan publik, fungsi pertahanan, fungsi ketertiban dan keamanan, fungsi ekonomi, fungsi lingkungan, fungsi perumahan dan fasilitas publik, fungsi kesehatan, fungsi pariwisata, fungsi keagamaan, fungsi pendidikan, dan fungsi perlindungan sosial. ${ }^{7}$

Pada tahun 2018 pengeluran APBN Negara sebesar Rp. 1.455,0 Triliun. Dengan pengeluran terbanyak di pelayanan umum sebesar 435,9 triliun, kedua Ekonomi sebesar 335,5 Triliun, Perlindungan sosial sebesar 162,6 Triliun, Pendidikan sebesar 147,6 Triliun, Ketertiban dan Keamanan sebesar 136,0 Triliun, Pertahanan sebesar 107,8 Triliun, Kesehatan sebesar 65,1 Triliun, Perumahan dan Fasilitas Umum sebesar 31,5 Triliun, Perlindungan Lingkungan Hidup sebesar 15,7 Triliun, Agama sebesar 9,5 Triliun dan Pariwisara sebesar 7,5 Triliun. ${ }^{8}$

\section{Gambar 1 Belanja Negara Tahun 2018}

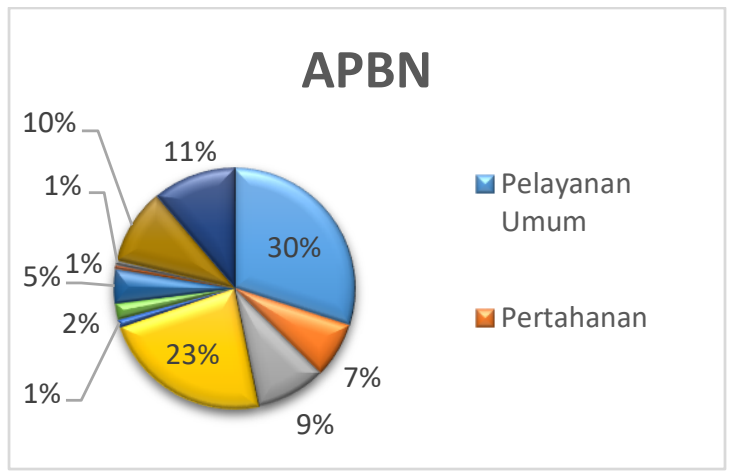

Sumber: (Kemenkeu, Informasi APBN, 2018)

Dengan demikian pengeluaran publik terbanyak pada pelayanan umum kepada masyarakat lainnya. Pengeluaran publik terbesar kedua adalah ekonomi, pengeluaran publik untuk ekonomi lebih terarah ke pemberantasan kemiskinan, penciptaan lapangan kerja serta kesejahteraan masyarakat. Ketiga perlindungan sosial, perlindungan sosial pada setiap masyarakat merupakan tanggung jawab dari pemerintah sehingga belanja Negara atau pengeluaran terhadap perlindungan sosial cukup banyak. Keempat

\footnotetext{
${ }^{7}$ Jaelani, A. (2017). Fiscal Policy in Indonesia: Analysis of State Budget 2017 in Islamic Economic Perspective. International Journal of Economics and Financial Issues , 14-24.

8 Kemenkeu. (2018). Informasi APBN. Retrieved from Kementrian Keuangan Republik Indonesia: www.anggarankemenkue.go.id
} 
pendidikan, suatu Negara yang maju atau berhasil dimana pendidikan merupakan nomor satu, tak hanya itu, pendidikan merupakan juga tagging jawab pemerintah untuk menjadikan penerus bangsa Indonesia ini berpendidikan yang tinggi. Lima pertahaan, dalam menjaga keamanan Negara pemerintah menjaga ketertiban Negara juga menjaga rakyat dari serangan-serangan musuh dari luar. Enam ketertiban dan Keamanan, ini juga merupakan tugas Negara yang harus dilaksanakan, karena salah satu tujuan negara adalah menciptakan ketertiban dan keamanan Negara. Tujuh kesehatan, kesehatan merupakan tugas negara, Negara harus memperhatikan kesehatan rakyat, Negara juga harus menjaga agar masyarakat terjaga kesehatannya dengan memenuhi kebutuhan pokok masyarakatnya. Delapan perumahan, perumahan merupakan tempat tinggal masyarakat sehingga pemerintah atau Negara harus menyediakan seperti rumah layak huni untuk masyarakat yang tidak mampu. Sembilan perlindungan lingkungan hidup, pemerintah harus menjaga lingkungan hidup agar masyarakat merasanya nyaman dengan lingkungan hidupnya. Sepuluh Agama dan Pariwisata, Indonesia memiliki 5 agama dan memiliki destinasi wisata yang begitu banyak dan Indah, dalam hal ini Negara juga harus bertanggung jawab untuk itu.

\section{Tujuan Anggaran Negara dalam Pandangan Maqasid Syariah}

Anggaran Negara adalah dokumen utama yang mencerminkan rencana keseluruhan pemerintah untuk tahun fiskal yang akan datang mengenai pengeluaran publik dan mobilisasi pendapatan. Pada saat yang sama, anggaran digunakan sebagai alat untuk pengawasan publik terhadap kinerja fiskal pemerintah. Ukuran keseluruhan anggaran dan komposisinya tidak hanya mencerminkan prioritas sosial dan ekonomi pemerintah, tetapi juga datang sebagai hasil dari proses politik, di mana peran dan kekuasaan yang berbeda ditugaskan dan didistribusikan di antara para pemain kunci yang terlibat dalam siklus anggaran. ${ }^{9}$

Kebijakan pengeluaran adalah unsur kebijakan fiscal di mana pemerintah atau negara membelanjakan pendapatan yang telah dikumpulkan. Pemerintah diharapkan dapat menggunakan keuangan tersebut dalam meningkatkan taraf hidup masyarakat dan ketakwaan. Kebijakan pengeluaran harus bisa menjamin pemenuhan kebutuhan pokok yang ditujukan kepada seluruh warga negara tanpa memandang agama, warna kulit, suku bangsa dan status sosial. Hanya saja intervensi negara melalui kebijakan fiscal diperlukan, berupa jaminan pemenuhan akan pangan, sandang dan papan, khusus ditunjukkan kepada warga negara miskin yang kepala keluarga dan ahli warisnya tidak mampu lagi memberikan nafkah yang memadai untuk memenuhi kebutuhan pokok keluarganya. Sedangkan warga negara yang berasal dari keluarga mampu tidak mendapatkan subsidi Negara. ${ }^{10}$

\footnotetext{
${ }^{9}$ Husseiny, I. A. (2015). The Quality of Egypt's State Budget: A Composite Index . European Journal of Economics, Finance and Administrative Sciences, 1450-2275.

${ }^{10}$ Huda dkk, N. (2011). Keuangan Publik Islami Pendekatan Teoritis dan Sejarah. Jakarta: Kharisma Putra Utama.
} 
Sistem penganggaran yang dipakai di dalam negara Islam adalah estimasi penerimaan yang wajar dari semua sumber negara dipersiapkan dengan hati-hati lalu kemudia didistribusikan bagi berbagai kategori pengeluaran. Dengan kata lain, basis penganggaran negara Islam adalah penerimaan, baru kemudian di alokasikan untuk pengeluaran. Sistem anggaran Islam itu sederhana saja, mudah dan logis, yakni anggaran mengalami surplus atau paling tidak seimbang.

Oleh karena itu dalam konsep ekonomi Islam, belanja negara harus sesuai dengan syari'iyyah dan penentuan skala prioritas. Para ulama terdahulu telah memberikan kaidah umum disarikan dari Al-Qur'an dan As Sunnah dalam memandu kebijakan belanja pemerintah. Kaidah-kaidah tersebut adalah sebagai berikut: 1). Menghindari masyaqqoh (Timbangan kebijakan pengeluaran atau belanja pemerintah harus senantiasa mengikuti kaidah Maslahah. 2). Menghindari Masyaqqoh (menurut Bahasa adalah ial-ta'ab, yaitu kelelahan, kepayahan, kesulitan dan kesukaran). Kesulitan dan mudarat harus didahulukan ketimbang melakukan pembenahan. 3). Mudarat individu dapat dijadikan alasan demi menghindari mudarat dalam skala umum. 4). Pengorbanan individu atau kerugian individu dapat dikorbankan demi menghindarkan kerugian dan pengorbanan dalam skala umum. 5). Kaidah "Algiurmu bil gunmi" yaitu kaidah yang menyatakan bahwa yang mendapatkan manfaat harus siap menanggung beban (yang ingin beruntung harus siap menanggung kerugian). 6). Kaidah "ma la yatimmu Al waajibu illa bihifahua wajib" yaitu kaidah yang menyatakan bahwa "sesuatu hal yang wajib ditegakkan, tanpa ditunjang oleh faktor penunjang lainnya tidak dapat dibangun, maka meninggalkan faktor penunjang tersebut menjadi wajib hukumnya. ${ }^{11}$

Tujuan pembelanjaan pemerintah dalam islam adalah sebagai berikut: Pertama, Pengeluaran demi memenuhi kebutuhan hajat masyarakat. Kedua Pengeluaran sebagai alat Redistribusi kekayaan. Ketiga Pengeluaran yang mengarah pada semakin bertambahnya permintaan efektif. Keempat Pengeluaran yang berkaitan dengan investasi dan produksi. Kelima Pengeluaran yang bertujuan menekan tingkat inflasi dengan kebijakan intervensi pasar. ${ }^{12}$

Kebijakan belanja umum Pemerintah dalam sistem ekonomi Syariah dapat dibagi menjadi tiga bagian sebagai berikut: 1). Belanja kebutuhan Operasional Pemerintah yang rutin, 2). Belanja umum yang dapat dilakukan pemerintah apabila sumber dananya tersedia. 3). Belanja umum yang berkaitan dengan proyek yang disepakati oleh masyarakat berikut sistem pendanaannya. ${ }^{13}$

\footnotetext{
${ }^{11}$ Huda dkk, N. (2011). Keuangan Publik Islami Pendekatan Teoritis dan Sejarah. Jakarta: Kharisma Putra Utama.

12 Huda dkk, N. (2011). Keuangan Publik Islami Pendekatan Teoritis dan Sejarah. Jakarta: Kharisma Putra Utama.

${ }^{13}$ Chaudhry, M. S. (2016). Prinsip Dasar Sistem Ekonomi Islam. Jakarta: Prenadamedia Group.
} 
Secara lebih rinci Pembelanjaan Negara harus didasarkan pada hal-hal berikut ini: Pertama Kebijakan belanja rutin harus sesuai dengan asas maslahat umum, tidak boleh dikaitkan dengan kemaslahatan seseorang atau kelompok masyarakat tertentu, apalagi kemaslahatan pejabat pemerintah. Kedua Kaidah atau prinsip efisiensi dalam belanja rutin, yaitu mendapatkan sebanyak mungkin manfaat dengan biaya yang semurahmurahnya, dengan sendirinya jauh dai sifat mubazir dan kikir disamping alokasinya pada sektor-sektor yang tidak bertentangan dengan syariah. Ketiga Kaidah yang tidak berpihak pada kelompok kaya dalam pembelanjaan, walaupun dibolehkan berpihak pada kelompok miskin. Keempat Kaidah atau prinsip komitmen dengan aturan syariah, maka alokasi belanja Negara hanya boleh pada hal-hal yang mubah, dan menjauhi yang haram. ${ }^{14}$

Kaidah atau prinsip komitmen dengan skala prioritas syariah, dimulai dari yang wajib, sunnah dan mubah, atau dhoruroh, hajiyyat dan kamaliyyah. Dalam Islam, pengeluaran publik untuk kepentingan publik didasarkan pada prinsip-prinsip manajemen anggaran pengeluaran yang rasional. Anggaran dikembangkan sesuai dengan pendapatan publik yang berasal dari sektor publik dan swasta kemudian didistribusikan ke berbagai kategori pengeluaran. Dengan demikian, prinsip anggaran adalah pendapatan yang tersedia untuk menentukan jumlah pengeluaran publik. Pengeluaran publik ditentukan oleh jumlah pendapatan yang tersedia dari sumber pendapatan yang tersedia. Anggaran biasanya surplus atau setidaknya anggaran berimbang. ${ }^{15}$ Pengeluaran anggaran APBN berkaitan dengan kebijakan fiskal, menurut Amir dalam dinamika respons kebijakan fiskal terhadap ketidakpastian global (dinamika kebijakan fiskal respons global) menggambarkan serangkaian kebijakan untuk merespons ketidakpastian global akibat krisis keuangan yang melanda dunia. ${ }^{16}$

Tujan dari pengeluaran publik di Indonesia hampir sama dengan tujuan pengeluran publik dalam pandangan maqasid syariah, akan tetapi dalam Islam kebijakan defisit tidak digunakan, karena dalam Islam mengantut kebijakan surplus, dimana penerimaan lebih banyak dari pada pengeluran. Dalam hal ini penile merangkum pengeluran publik Islam yang sesuai dengan tujuan syariah yaitu sebagai berikut:

${ }^{14}$ Chaudhry, M. S. (2016). Prinsip Dasar Sistem Ekonomi Islam. Jakarta: Prenadamedia Group.

${ }^{15}$ Jaelani, A. (2017). Fiscal Policy in Indonesia: Analysis of State Budget 2017 in Islamic Economic Perspective. International Journal of Economics and Financial Issues , 14-24.

${ }^{16}$ Amir, \& Faisal, H. (2016). Dinamika Kebijakan Fiskal Merespon Ketidakpastian Global. Jakarta: Gramedia Pustaka Utama. 


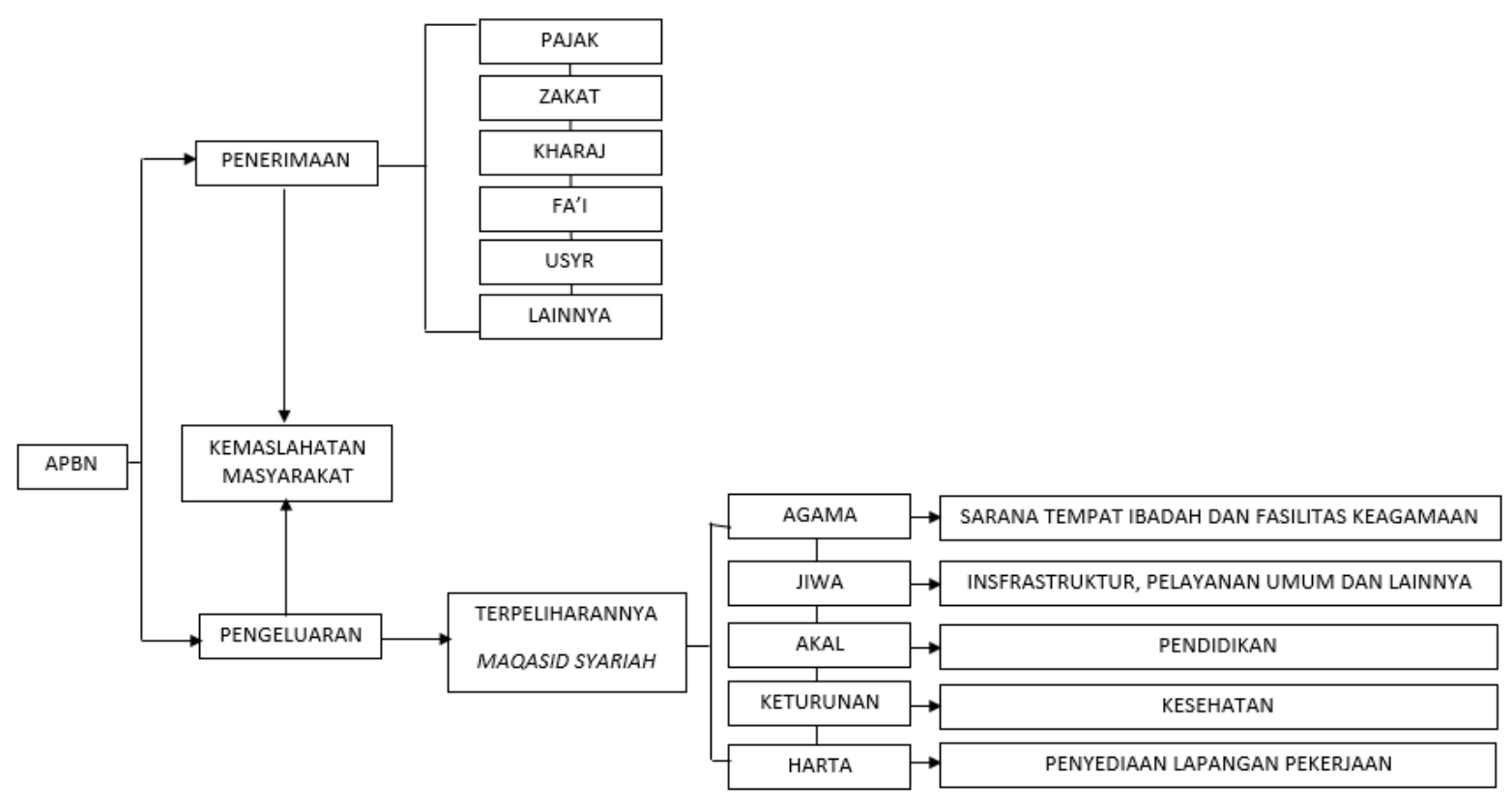

Gambar 2 Struktur Anggaran dengan Prinsip Maqasid Syraiah

Sumber: Penulis

Maqasid Syariah dalam pengeluran publik sesuai dengan tujuan syariah yaitu untuk kemaslahatan umat. Selain itu dalam Islam 5 tujuan maqasid syariah harus terpenuhi untuk pengeluaran publik. Terpenuhinya tujuan maqasid syariah yaitu agama, akal,

Gambar diatas dapat disimpulkan bahwa pengalokasian APBN dalam pandangan Maqasid Syari'ah untuk Kemaslahatan Masyarakat yang tinggal di daerah tersebut tanpa terkecuali, sehingga terpeliharanya tujuan Syariah yaitu agama, Jiwa, Akal, Keturunan dan Harta, pengalokasian dana APBN dalam hal ini untuk 5 tujuan Maqasid Syari'ah ini. Pertama Agama: agama merupakan landasan pertama maqasid syariah. Anggaran pengeluaran APBN untuk mendirikan tempat-tempat ibadah, fasilitas-fasilitas Ibadah, dan pemberdayaan atau anggaran untuk para pakar agama dalam menyiarkan agama. Kedua Jiwa: jiwa menyangkut nyawa manusia. Dalam hal ini pemerintah berkewajiban menjamin nyawa manusia, dengan memberikan asuransi kematian, selain itu memperbaiki jalan-jalan rusak atau jembatan juga masuk ke dalam kategori menjaga jiwa, karena dengan jalanan-jalanan yang bagus akan menghindari dari kecelakaan lalu lintas serta memberikan fasilitas kesehatan. Ketiga Akal: dengan peningkatan kualitas pendidikan, seperti pembagian buku-buku gratis untuk anak-anak sekolah, sekolah gratis serta beasiswa. Keempat Harta: penyediaan lapangan kerja, membuat pelatihan terkait kompetensi diri masyarakat sehingga masyarakat dapat membuka wirausaha sendiri.

Dapat dilihat bahwasanya tujuan pengeluran publik di Indonesia secara umum sudah sesuai dengan maqasid syariah, akan tetapi belum sepenuhnya sesuai dengan tujuan Islam, seperti dalam hal agama, dalam Islam agama menjadi puncak untuk pengeluaran publik, sedangkan pada pengeluaran publik Indonesia agama mendapatkan porsi yang 
sangat sedikit, selain itu dalam Islam juga mengaut system surplus, dan Indonesia defisit, ini menjadikan tujuan dalam pengeluaran anggaran menjadi sedikit berbeda

\section{KESIMPULAN}

Manajemen pengeluaran publik di Indonesia telah menerapkan system distribusi yang membagi pengeluaran publik untuk pengeluaran pemerintah pusat, transfer ke daerah, dan dana desa. Dalam hal ini priorotas kebijakan fiskal kepada pengeluaran publik untuk mendukung pencapaian pertumbuhan ekonomi yang berkelanjutan, penciptaan lapangan pekerjaan, pengurangan kemiskinan, dan pengurangan kesenjangan dalam kesejahteraan seluruh masyarakat. Pengalokasian APBN dalam pandangan Maqasid Syari'ah untuk Kemaslahatan Masyarakat yang tinggal di daerah tersebut tanpa terkecuali, sehingga terpeliharanya tujuan Syariah yaitu agama, Jiwa, Akal, Keturunan dan Harta, tujuan pengeluran publik di Indonesia secara umum sudah sesuai dengan maqasid syariah, akan tetapi belum sepenuhnya sesuai dengan tujuan Islam, seperyi dalam hal agama, dalam Islam agama menjadi puncak untuk pengeluaran publik, sedangkan pada pengeluaran publik Indonesia agama mendapatkan porsi yang sangat sedikit, selain itu dalam Islam juga mengaut system surplus, dan Indonesia defisit, ini menjadikan tujuan dalam pengeluaran anggaran menjadi sedikit berbeda.

\section{DAFTAR PUSTAKA}

Ajibolade, S. O., \& Oboh, C. S. (2017). A critical examination of government budgeting and public funds management in Nigeria . International Journal of Public Leadership, 218-242.

Amir, \& Faisal, H. (2016). Dinamika Kebijakan Fiskal Merespon Ketidakpastian Global. Jakarta: Gramedia Pustaka Utama.

Chaudhry, M. S. (2016). Prinsip Dasar Sistem Ekonomi Islam. Jakarta: Prenadamedia Group.

Furukawa, M., \& Takahata, J. (2018). General Budget Support in Tanzania Implications of late disbursements for service delivery . African Journal of Economic and Management Studies , 477-491.

Huda dkk, N. (2011). Keuangan Publik Islami Pendekatan Teoritis dan Sejarah. Jakarta: Kharisma Putra Utama.

Husseiny, I. A. (2015). The Quality of Egypt's State Budget: A Composite Index . European Journal of Economics, Finance and Administrative Sciences , 1450-2275.

Jaelani, A. (2017). Fiscal Policy in Indonesia: Analysis of State Budget 2017 in Islamic Economic Perspective. International Journal of Economics and Financial Issues , 1424.

Jaelani, A. (2018). Public Expenditure Management in Indonesia: Islamic economic review on state budget 2017. Hunafa Jurnal Studia Islamika, 189-404.

Kemenkeu. (2018). Informasi APBN. Retrieved from Kementrian Keuangan Republik Indonesia: www.anggarankemenkue.go.id 
Kemenkeu. (2018). Informasi APBN. Retrieved from Kementrian Keuangan Republik Indonesia: www.anggarankemenkue.go.id 